\title{
Sandviç Malzeme Geliştirmede Polimer Köpük Çekirdek Kalınlığının Eğilme Dayanımına Etkisinin Deneysel olarak Araştırılması
}

\author{
Necdet GEREN ${ }^{1}$, Çăgrı UZAY ${ }^{* 1}$, Mete Han BOZTEPE ${ }^{1}$, Melih BAYRAMOĞLU ${ }^{1}$ \\ ${ }^{1}$ Çukurova Üniversitesi, Mühendislik Mimarlık Fakültesi, Makine Mühendisliği Bölümü, Adana
}

Geliş tarihi: $04.01 .2017 \quad$ Kabul tarihi: 31.05 .2017

$\ddot{\mathbf{O z}}$

Hibrit malzeme sınıflandırma kategorilerinden biri olan sandviç yapılar, oldukça hafif ve eğilme rijitliği çok yüksek teknolojik malzemelerin elde edilmesine olanak sağlamaktadır. Literatürde ileri seviye kompozit malzemeler olarak adlandırılan bu yapılar, otomotiv, havacılık, gemi ve savunma endüstrileri gibi alanların yenilikçi malzemeleridir. Bu çalışmada farklı çekirdek kalınlığına sahip PVC köpük malzemesi ve örgü dizilimli karbon elyaf kumaşları kullanılarak bir epoksi matris ile sandviç plakalar üretilmiş ve çekirdek kalınlığının eğilme direncine olan etkisi araştırılmıştır. ASTM C393/M 393C standardında belirtilen boyutlarda elde edilen numuneler üç nokta eğilme testine tabi tutulmuştur. Testler sonucunda numune ağırlı̆̆ında fazla artış olmamasına rağmen malzemenin yük taşıma kapasitesinde iyileşme olduğu gözlemlenmiştir. Ayrıca, malzemede meydana gelen hasar durumu da incelenmiştir.

Anahtar Kelimeler: Kompozit, Sandviç yapılar, Çekirdek kalınlığı, Eğilme direnci

\section{An Experimental Investigation of the Effect of Core Thickness on Bending Resistance in Development of Polymer Foam Core Sandwich Structures}

\begin{abstract}
Sandwich structures which are categorized under the hybrid materials, provide to obtain very light-weigth and very high resistance to bending when compared to commonly used laminated composite materials. These structures are now called as advanced composite materials and newly used in automotive, aviation, marine and defense industries. In this study, sandwich plates having different core thicknesses and were fabricated with carbonfiber skins and epoxy matrix and the effect of core thickness on bending resistance was investigated. The test specimens were cut according to standard dimensions provided in ASTM C393/M 393C standard then subjected to three point bending test. The results of the tests showed that there is a good improvement on bending resistance of the materials although the weight of the specimens was not increased much. Also, the failure modes occured on the materials was examined.
\end{abstract}

Keywords: Composite, Sandwich structures, Core thickness, Bending resistance

*Sorumlu yazar (Corresponding author): Çağrı UZAY, cuzay@cu.edu.tr 


\section{GíRiş}

Otomotiv, uçak-uzay, gemi makineleri gibi birçok mühendislik alanında kullanılan metalik malzemeler, gelişen teknoloji ile birlikte yerini yapısal anlamda çok daha hafif, daha rijit ve aynı zamanda daha dayanıklı hibrit yapılı malzemelere bırakmaktadır. $\mathrm{Bu}$ yüzden hibrit yapılı malzemelerin de üretilmeye başlanması ve endüstriyel alanda kullanım imkanlarının geliştirilmesi gibi çalışmalar daha çok önem kazanmıştır. Hibrit yapılı malzemeler 4 sınıfa ayrılır; kompozit, sandviç, hücresel ve dilimli veya bölümlü [Asy1]. Sandviç malzemeler, ikiden fazla malzemenin bağlayıcı bir matrisle birleştirilerek katmanlarda yer alan tekil malzemelerin herhangi birinden oldukça hafif ve eğilme rijitliği çok yüksek teknolojik malzemelerin elde edilmesine olanak sağlamaktadır. En yaygın olarak bilinen kompozitler ise elyaf takviyeli polimer matrisli tabakalı kompozitlerdir [1]. Son zamanlarda ise farklı elyaf kumaşlar veya ince alaşımlı metal malzemelerin arasına, balpeteği, oluklu levhalar veya endüstriyel yapıda metalik ya da polimer esaslı köpük malzemeleri yerleştirilerek yeni sandviç malzemeler üretilmektedir. Buna bağlı olarak da yeni sandviç yapıların üretimi ve dayanımlarının belirlenmesi yönündeki araştırmalar artmaktadır. Sandviç yapıyı meydana getiren yüzey ve çekirdek tabakaları Şekil 1'de gösterilmektedir. Burada "d" sandviç kalınlığını, "t" ve "c" ise sırasıyla yüzey ve çekirdek malzeme kalınlığnı belirtmektedir.

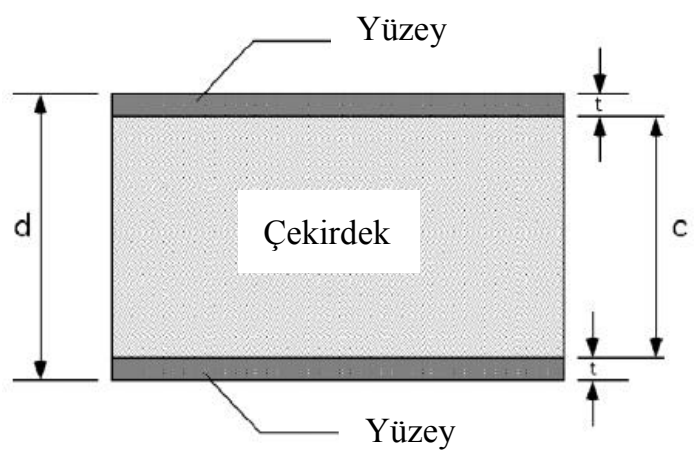

Şekil 1. Sandviç yapıyı meydana getiren yüzey ve çekirdek tabakaları
Sandviç yapılarda dış yüzeylerde oldukça ince, dayanımı yüksek metal alaşımları veya kompozit elyaf kumaşlar kullanılırken ara katmanda ise nispeten daha kalın, düşük mukavemetli, ancak hafif ve çekirdek olarak adlandırılan balpeteği, oluklu levhalar, balsa ağacı veya endüstriyel yapıda metalik ya da polimer esaslı köpük gibi malzemeler kullanılır. Farklı türden malzemelerin meydana getirdiği bu yapı, bağlayıcı bir matrisle yapıştırılır. Ve sonucunda, hali hazırda kullanılan bir metalik levhaya veya bilinen tabakalı kompozitlere kıyasla çok daha hafif, rijit ve eğilme dirençleri oldukça yüksek malzemeler elde edilir. Sandviç yapıları önemli kılan diğer özellikler ise uygun malzeme kombinasyonu ile düşük maliyet elde edilmesi, termal yalıtım özelliği, ses yalıtım özelliği, radar dalgalarına yakalanmaması, uygun aerodinamik yüzeyler oluşturabilmesi ve yüksek hızlara dayanımdır [2].

Yapıyı oluşturan ana elemanların görevlerine bakıldığında, yüzeyler, sandviç yapı içerisindeki basma ve çekme gerilmelerini taşımada dayanım sağlarken [3], çekirdek ise yüzeyler arası mesafeyi koruyup dengede tutarak eğilmeye, basma yüklerine ve düzlem dışı kaymalara karşı rijitlik sağlamaktadır. Yüzeylerin birbirleri üzerinde kaymaması için çekirdek, kayma kuvvetlerine karşı çok dirençli olmalıdır. Kayma rijitliği yüzeyleri birbirleriyle hareket etmemeye zorlamaktadır. Eğer çekirdek kayma kuvvetlerine karşı zayıfsa yüzeyler birlikte hareket eder ve sandviç rijitliğini kaybeder. Yüzeyler aynı zamanda bölgesel basınçları da taşımaktadır. Bölgesel basınç yükleri yüksek olduğunda yüzeyler kayma kuvvetleri için bölgesel basınçlara bağlı olarak boyutlandırılmalıdır $[4,5]$.

\section{2. ÖNCEKİ ÇALIŞMALAR}

Yüksek dayanım-ağırlık oranına sahip olması, dinamik yüklere karşı daha iyi rijitlik göstermesi, çevresel etkilerden dolayı oluşabilecek bozunmalara karşı dirençli olması gibi özellikler sandviç yapılara farklı mühendislik alanlarından uygulama firsatı vermekte ve birçok araştırmacının yoğun ilgisini çekmektedir. İstenilen mekanik özelliklerin elde edilmesinde göz önünde 
bulundurulacak tasarım faktörleri şu şekildedir: elyaf kumaş türü, elyaf/matris oranı, elyaf dokumalarının açısal dizilimi, katman sayısı, matris türü, çekirdek türü, yoğunluğu ve kalınlığıdır [6]. Örneğin ısı ve ses yalıtımında veya enerjiyi absorbe etme noktasında alüminyum köpükler kullanılmıştır [7]. Bazı araştırmacılar statik ve dinamik yükler altında sandviç yapıların hasar davranışlarını incelemişlerdir. Basma yükü altında hasarlar, tabaka ayrılması, batma, tabakaların buruşması, çekirdek malzeme kayması şeklindeki hasarlar başlıca hasar tipleri olarak belirlenmiştir [5, 7-10]. Zabihpoor ve arkadaşları [11] karbon ve cam elyafindan oluşan hibrit yüzey tabakaları ve PVC köpük çekirdek malzemesinden oluşan sandviç yap1 üretip, çekme-çekme yükleri altında S-N grafiğini çıkarmıştır. Atas ve Sevim [12] yüzey tabakası olarak cam elyafı ve çekirdek malzeme olarak balsa ağacı ile PVC köpük kullanarak darbe yükleri altında hasar durumunu incelemiş ve balsa ağacı malzemesiyle cam elyafi arasındaki ara yüzeyin zayıf oluşuna dikkat çekmiştir.

Aynı elyaf türünün farklı açısal dizilimlerine sahip kumaşları da sonuçları değiştirmektedir. Bey ve ark. [13] 0-90 derece ve sadece sifir derece gibi farklı açısal dizilişte cam elyafı ve PVC köpük malzemelerinden sandviç panel üretmiş ve numuneleri 3 nokta eğilme testine tabi tutmuştur. 0-90 derece açısal dizilime sahip numunenin daha rijit olduğunu ve yorulma yükleri altında diğerine göre daha etkili olduğunu belirtmiştir. Diğer bir taraftan çekirdek malzemesinin türü ve kalınlığı da sandviç yapıda istenilecek fiziksel ve mekanik özelliklerin elde edilmesinde önem arz eden araştırma konusudur [14-16]. Zhou ve arkadaşları [14] farklı türden polimer köpükler ile üretilen sandviç panelleri düşük hız darbe testine tabi tutmuş ve batma direncinin köpük türüyle ilişkili olduğunu güçlü bir şekilde ortaya koymuşlardır. Özdemir ve arkadaşları [15] iki farklı PVC ve PET köpük malzemeyi çekirdek malzeme olarak kullanarak bunların farklı kalınlıklardaki etkilerini incelemiştir. Düşük çekirdek malzeme kalınlıklarında darbe yüklerine neredeyse herhangi bir etkisinin olmadığını ancak kalınlığı nispeten fazla olan sandviç yapıların ise daha fazla darbe enerjisini absorbe ettiğini tespit etmiştir.
İlaveten eğilme yüklerine karșı PVC çekirdek malzemesinin PET'e göre daha dirençli olduğu görülmüştür. Styles ve arkadaşları [16] çekirdek malzeme olarak farklı kalınlıklarda alüminyum köpük kullanmış ve köpük kalınlığı arttıkça yapının taşıyabileceği maksimum yükün de arttığ1 ve buna bağlı olarak da eğilme rijitliğinin arttığını belirlemiştir. Lim ve arkadaşları [9] ise aynı çekirdek kalınlığında 4 farklı yüzey kalınlığının statik ve darbe yükleri altındaki davranışlarını incelemişler ve ince yüzey katmanının basmaya maruz kalarak kırılması şeklinde göstermişlerdir.

Literatür çalışmalarına bakıldığında belirli mekanik özellikler için belirli konfigürasyonlar yapıldı ̆̆ı anlaşılmaktadır. Örneğin; darbe direncini iyileştirme, 1sı ve ses yalıtımı sağlama gibi özelliklerin elde edilmesi için alüminyum köpük kullanılırken, rijitlik ve eğilme direncini iyileştirmede ise polimer esaslı köpükler çekirdek malzeme olarak kullanılmıştır. Ancak yapılan çalışmalarda genellikle test standardı belirtilmemiş olup çeşitli boyutlarda üretilen sandviç yapılar kullanılmıştır. Bu da farklı sonuçların doğmasına ve kıyaslama yaparken birtakım tutarsızlıklara sebep olmaktadir.

$\mathrm{Bu}$ çalışmada çekirdek olarak kullanılan polimer köpük malzemesi düşük yoğunluklu olup literatürde fazla rastlanmamaktadır. Çalışmada test edilen sandviç yapılar ASTM C393/M 393C-11 [17] Standardında belirtilen ölçülerde üretilmiş ve standartta yazılı koşullarda teste tabi tutulmuştur. Çalışmanın amacı ise çekirdek kalınlığının eğilme direnci üzerindeki etkisinin deneysel olarak araştırılmasıdır.

\section{MATERYAL VE METOT}

\subsection{Materyal}

Bu çalışmada farklı çekirdek kalınlıklarına sahip Polyvinylchloride (PVC) köpük malzemesi ve karbon elyaf kumaşlar kullanılarak belirli bir epoksi matris ile sandviç plakalar üretilmiştir. Üretim için kullanılan ham malzemelere ait fiziksel özellikler Çizelge 1, 2 ve 3'te bulunmaktadır. 
Sandviç Malzeme Geliştirmede Polimer Köpük Çekirdek Kalınlığının Eğilme Dayanımına Etkisinin Deneysel olarak Araştırılması

Çizelge 1. Karbon elyaflı kumaşın fiziksel özellikleri

\begin{tabular}{|c|c|c|}
\hline $\begin{array}{c}\text { Açısal } \\
\text { dizilim }\end{array}$ & $\begin{array}{c}\text { Katman } \\
\text { kalınlı̆̆ }, \\
\mathbf{m m}\end{array}$ & $\begin{array}{c}\text { Alansal } \\
\text { yoğunluk, } \\
\mathbf{g} / \mathbf{m}^{\mathbf{2}}\end{array}$ \\
\hline örgü & 0,25 & 200 \\
\hline
\end{tabular}

Çizelge 2. Çekirdek malzeme fiziksel özellikleri

\begin{tabular}{|c|c|c|}
\hline $\begin{array}{c}\text { PVC } \\
\text { köpük }\end{array}$ & Yoğunluk, $\mathbf{k g} / \mathbf{m}^{\mathbf{3}}$ & Kalınlık, mm \\
\hline C70.48 & 48 & $16-20-26$ \\
\hline
\end{tabular}

Çizelge 3. Matris bileşenleri ve fiziksel özellikleri

\begin{tabular}{|c|c|c|}
\hline $\begin{array}{l}\text { Kimyasal } \\
\text { Malzeme }\end{array}$ & $\begin{array}{c}\text { Yoğunluk, } \\
\text { kg/m } \mathbf{m}^{3}\end{array}$ & $\begin{array}{c}\text { Vizkozite, } \\
\text { mPas }\end{array}$ \\
\hline Epoxy reçine & $1130-1170$ & 700-900 \\
\hline Sertleştirici & $960-1000$ & $10-50$ \\
\hline
\end{tabular}

Çizelge 1-3'te belirtilen elyaf kumaş ve çekirdek malzemeler kullanılarak 3 farklı türde sandviç plakalar üretilmiştir. Çizelge $4^{\text {'te }}$ üretimi gerçekleştirilen plakaların numune kodları ve açıklaması mevcuttur.

\subsection{Ham Malzemelerin Hazırlanması ve Üretim}

ASTM C393/C393M - 11 standardında sandviç paneller için 3 nokta eğilme testi tarif edilmiş ve standart numune boyutları belirtilmiştir. Şekil 2'de görüldüğü gibi numune boyutları $75 \mathrm{~mm} \mathrm{x}$ 200 mm'dir. Üretimden sonra numunelerin standart boyutlarda hassas bir şekilde kesilebilmesi ve numune boyutlarına zarar vermemesi için elyaf ve köpük malzemeler $200 \mathrm{~mm} \quad$ x $255 \mathrm{~mm}$ ölçülerinde kesilmiştir. Testler üçer kez tekrarlandığı için sandviç plakalar 3 numuneyi kapsayacak şekilde üretilmiştir. Reçine seti MGS laminasyon L160 epoksi ve H160 sertleştirici içermektedir. Karışım, 100:25 oranında hazırlanmıștır. Üretim esnasında ise elyaf ve reçine oranı yaklaşı 50:50 şeklindedir.

Çizelge 4'te belirtilen konfigürasyonlara karar verildikten sonra üretim prosesine geçilmiştir. Üretim adımları sırası ile şu şekilde gerçekleştirilmiş̧ir;
1. Elyaflarin Kesilmesi ve hassas terazi ile tartılmast.

2. Reçine miktarının belirlenmesi. Uygun reçine miktarının belirlenmesinde elyaf ağırlığının tespit edilmiş olması gerekmektedir. Aksi halde üretim esnasında reçine yetersiz kalabilir, üretim süreci başarısızlığa uğrayabilir.

3. Epoksi ve sertleştircisi ile hazırlanan reçinenin kimyasal reaksiyonun gerçekleşmesi.

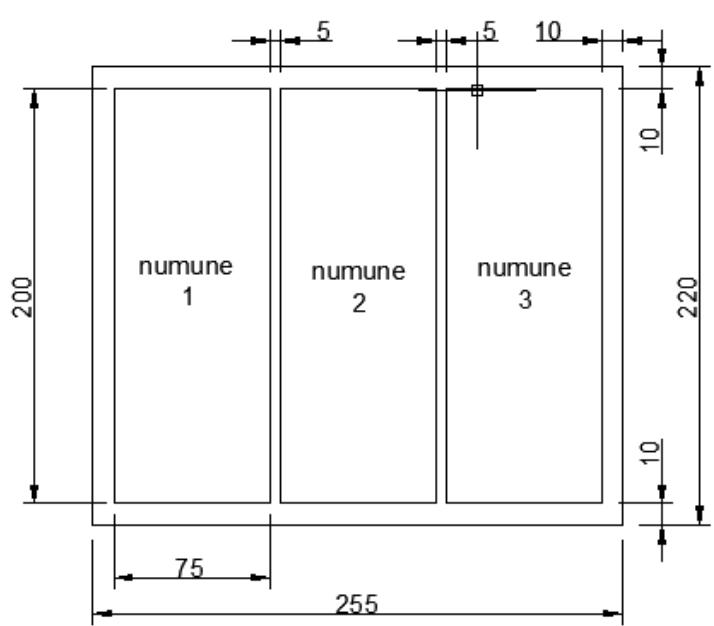

Şekil 2. Standart test numunesi boyutları ve üretim için kesilen elyaf ve köpük ölçüleri

Elyaf ağırlığı kadar hazırlanan reçine, sertleştiricinin homojen bir şekilde kabın içine dağılması için yaklaşık $5 \mathrm{dk}$ boyunca yavaşça karıştırılır, Şekil 3(b) elde edilir.

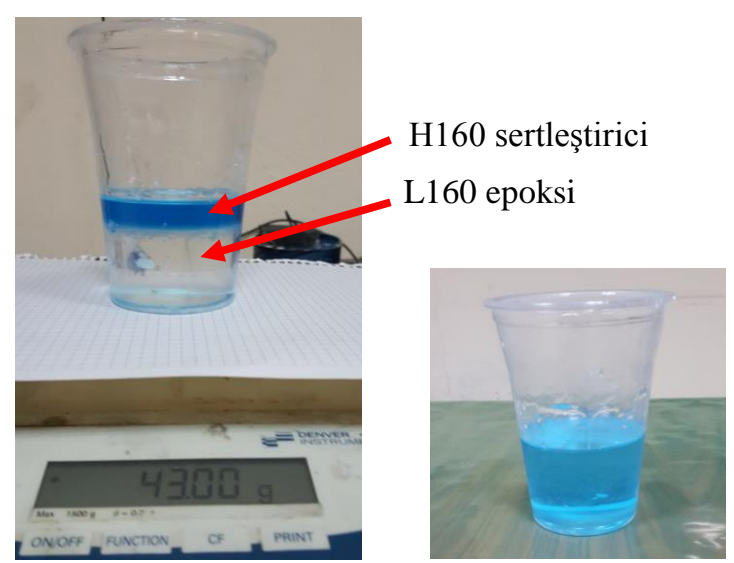

Şekil 3. Epoksi ve sertleştirici için kimyasal reaksiyonunun gerçekleşmesi 
4. El yatırma yönteminin uygulanmast. Uygun bir zemin hazırlandıktan sonra alt katmanı oluşturan elyaf serilir ve yüzeyine reçine uygulanır. Ara katmana sıra geldiğinde ise çekirdek köpük malzemesi yerleştirilir ve aynı şekilde reçine uygulaması yapılır. Bu şekilde son elyaf katmanı da tamamlanana kadar süreç devam ettirilir (Şekil 4). Reçinenin kap içerisinde de kürlenmesi devam ettiğinden dolayı, kimyasal yapısının bozulmaması için el yatırma yönteminde seri bir şekilde hareket edilmelidir.

Çizelge 4. Üretimi yapılan sandviç panellerin isimlendirilmesi ve açıklaması

\begin{tabular}{|c|l|l|}
\hline Sira. No. & \multicolumn{1}{|c|}{ Numune kodu } & \multicolumn{1}{c|}{ Açıklaması } \\
\hline 1 & CF.W.P3.D8.T26 & Karbonelyaf - 3 kat örgü kumaş - C70.48 - 26 mm çekirdek \\
\hline 2 & CF.W.P3.D8.T20 & Karbonelyaf - 3 kat örgü kumaş - C70.48 - 20 mm çekirdek \\
\hline 3 & CF.W.P3.D8.T16 & Karbonelyaf - 3 kat örgü kumaş - C70.48 - 16 mm çekirdek \\
\hline
\end{tabular}

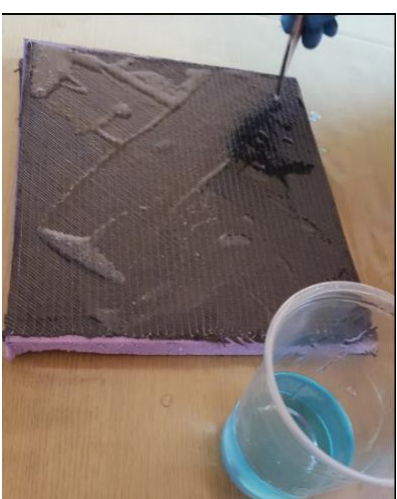

Şekil 4. El yatırma yönteminin uygulanması

5. Vakum torbalama için hazırlık. El yatırma tamamlandiktan sonra soyma naylonu ve vakum battaniyesi panellerin üzerine serilir. Bunun amacı kürlenme sırasında açığa çıkacak fazla reçineyi kontrollü bir şekilde panelden uzaklaştırmaktır (Şekil 5).

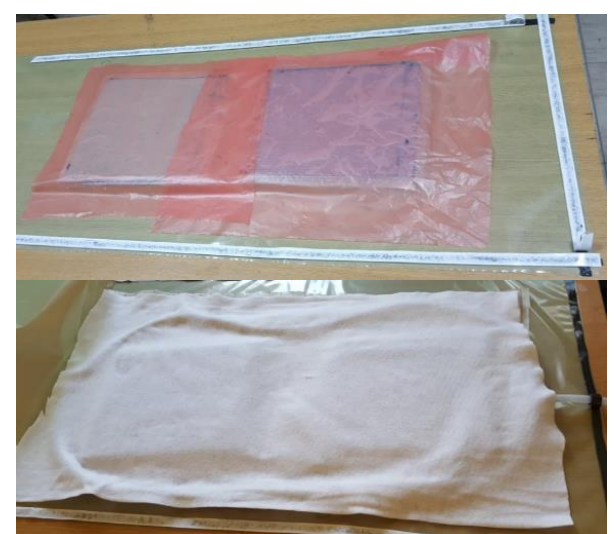

Şekil 5. Vakum torbalama için hazırlık
6. Vakumlama. Şekil 6'da görüldüğü gibi hazırlanan sandviç paneller vakum torbası arasında kalacak şekilde sızdırmaz bantlarla kapatılır. Ve vakum pompası çalıştırılır.

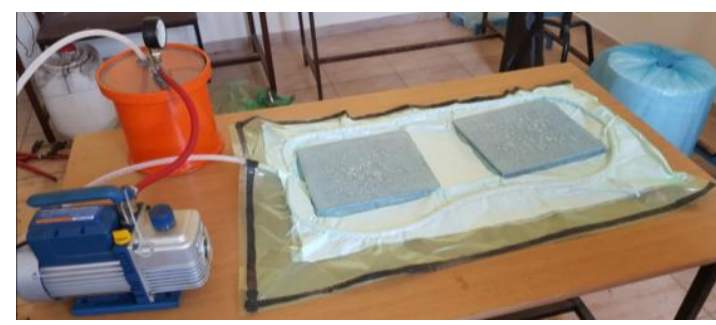

Şekil 6. Vakum pompasının çalıştırılması

7. Kürlenme. Vakum pompası yaklaşık $45 \mathrm{dk}$ boyunca çalıştırılır ve kapatılır. Kapatmadan önce sandviç panellerin vakum torbası içerisindeki reçine akışı gözlemlenmelidir. Reçine akışı devam ediyorsa pompa çalışmaya devam etmeli, reçine akışı durmuş ise pompa kapatılarak torba içine giden hortum hava almayacak şekilde sıkılmalıdır. Şekil 7'de olduğu gibi sandviç paneller kürlenmeye bırakılmalıdır. Kürlenme süresi 24 saate kadar çıkabilmektedir.

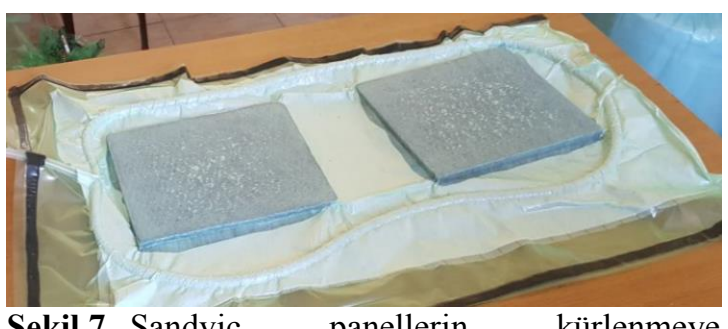

Şekil 7. Sandviç panellerin kürlenmeye birakılması 
Sandviç Malzeme Geliştirmede Polimer Köpük Çekirdek Kalınlığının Eğilme Dayanımına Etkisinin Deneysel olarak Araştırılması

\subsection{Test Numunelerinin Elde Edilmesi}

Üretimi tamamlanan sandviç plakalar ASTM C393/C393M - 11 Standardında belirtilen boyutlara kesilmiştir. Şekil 8'de görüldüğü gibi boyut hassasiyetini korumak için numuneler su jeti kesim yöntemi kullanılarak elde edilmiştir.

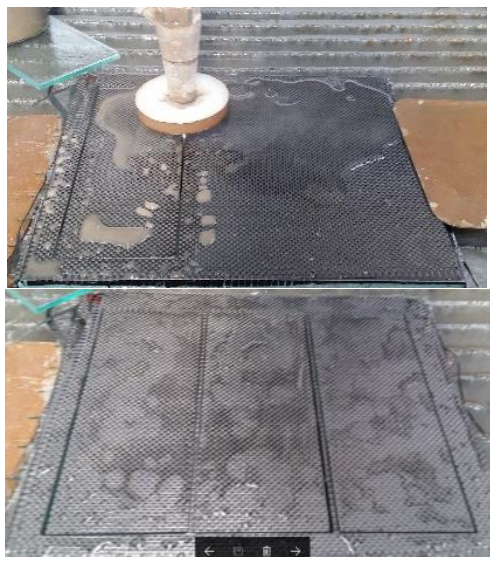

Şekil 8. Su jeti ile kesilen test numunelerinin hazırlanmas

Plakalar kesildikten sonra her bir test numunesinin kalınlıkları ve ağırlıkları ölçülmüş ve ortalama değerleri Çizelge 5'te verilmiştir.

Çizelge 5. Test numunelerinin kalınlığı ve ağırlıkları

\begin{tabular}{|c|c|c|c|}
\hline No. & Numune kodu & Kalınlık, mm & Ăgırlık, gr \\
\hline 1 & CF.W.P3.D8.T26 & 27,1 & 45,86 \\
\hline 2 & CF.W.P3.D8.T20 & 21,12 & 43,50 \\
\hline 3 & CF.W.P3.D8.T16 & 17,35 & 38,44 \\
\hline
\end{tabular}

\section{4. Üç Nokta Eğilme Testi}

Literatürde de belirtildiği gibi sandviç yapılı kompozit malzemelerin başlıca faydası eğilme dirençlerinin iyi olmasıdır. Eğilme direncini belirlemek için yaygın olarak bilinen üç nokta veya dört nokta eğilme testleri yapılmaktdır. Bu çalışmada üç nokta eğilme testi yapılmış olup testler, ASTM C393/C393M - 11 Standardına göre gerçekleştirilmiş̧ir. Şekil 9, sandviç plakaların üç nokta eğilme testinde kullanılan standart konfigürasyonunu temsil etmektedir.

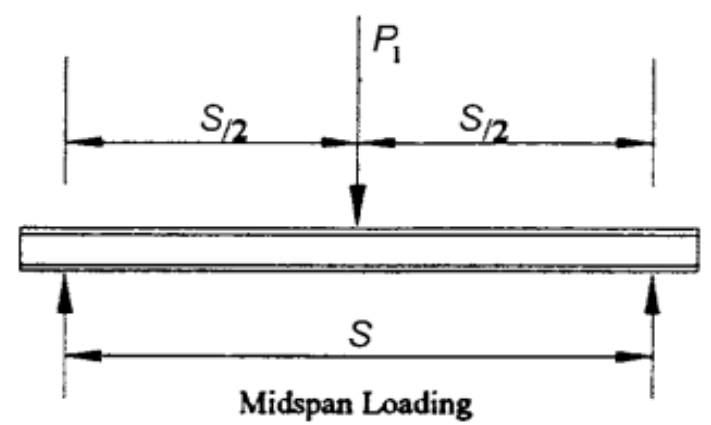

Şekil 9. Üç nokta eğilme testi, standart test konfigürasyonu $(\mathrm{S}=150 \mathrm{~mm})$

Numuneler, 100 kN yük kapasiteli Shimadzu Autograph (AG IS) cihazında test edilmiştir (Şekil 10). ASTM C393/C393M - 11 Standardında belirtildiği üzere basma hızı $6 \mathrm{~mm} / \mathrm{dk}$ olarak ayarlanmıştır.

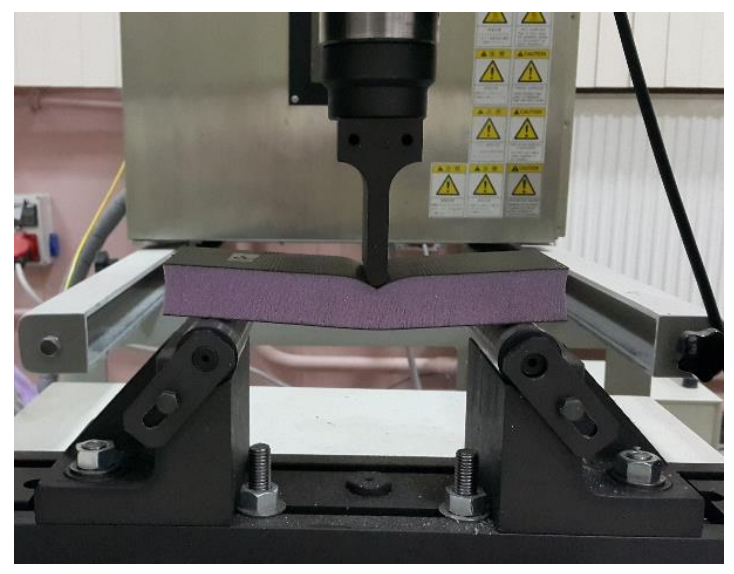

Şekil 10. Shimadzu Autograph (AG IS, $100 \mathrm{kN}$ ) test cihazında testlerin gerçekleştirilmesi

\section{BULGULAR}

\section{1. Üç Nokta Eğilme Testi Sonuçları}

3 farklı kombinasyona sahip sandviç malzeme plakaları her birinden üçer numune olmak üzere toplam $9 \mathrm{kez}$ eğilme testi yapılmış ve numunelere ait kuvvet-deplasman (numune uzunluğuna dik doğrultudaki) eğrileri elde edilmiştir. Şekil 11'de farklı çekirdek kalınlığına sahip numunelerin eğilme yükleri altındaki davranışları karşılaştırılmalı olarak verilmiş̧ir. 
Ayrica, ASTM C393/C393M - 11 test standardına göre çekirdek maksimum kayma dayanımı (core shear ultimate strength) ve yüzey gerilmesi de (facing stress) belirlenebilir. Eşitlik 1 ile çekirdek maksimum kayma dayanımı, Eşitlik 2 ile yüzey gerilmesi ASTM standardına göre hesaplanabilmektedir.

$$
F_{S}^{u l t}=\frac{P_{\max }}{(d+c) b}
$$

$F_{S}^{u l t}=$ çekirdek maksimum kayma dayanımı, $M P a$

$P_{\text {max }}=$ maksimum kuvvet, $N$ (hasardan önce)

$d=$ sandviç kalınlı̆̆ $\mathrm{l}, \mathrm{mm}$

$c=$ çekirdek kalınlığl, $\mathrm{mm}$

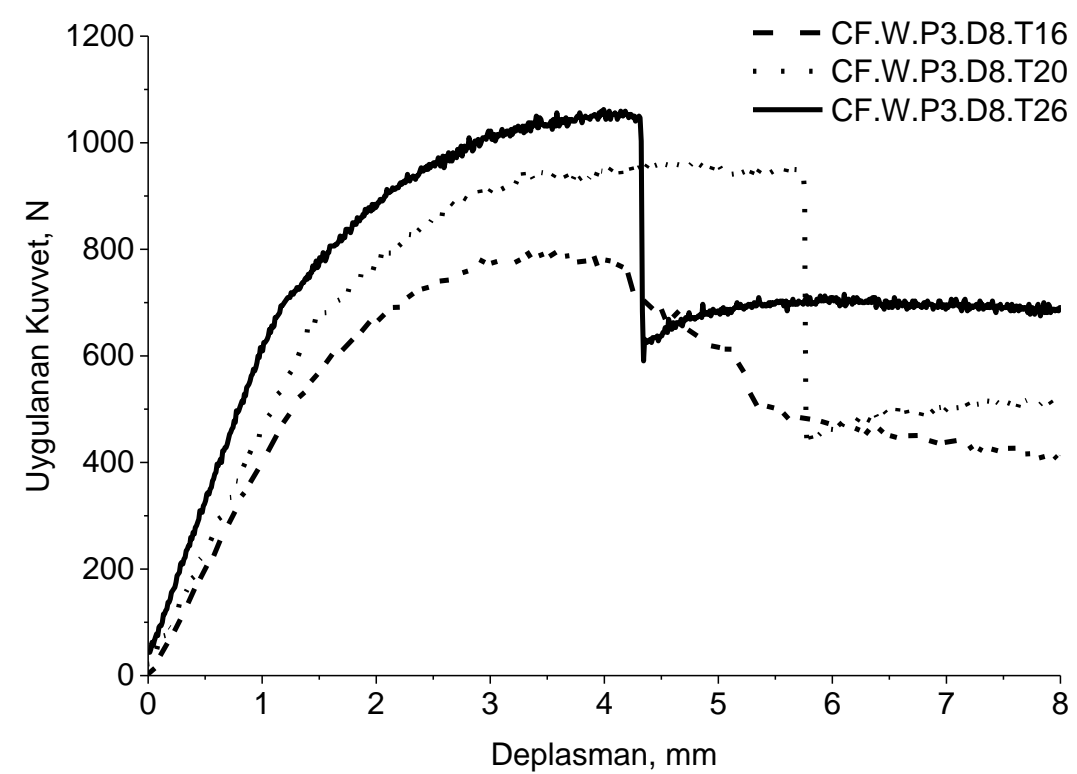

Şekil 11. Farklı çekirdek kalınlıklarına sahip sandviç plakaların kuvvet-deplasman eğrileri

Çizelge 6. Sandviç yapıların maksimum kuvvet, çekirdek maksimum kayma dayanımı ve yüzey gerilmelerine dair hesaplamalar

\begin{tabular}{|c|c|c|c|c|c|c|c|}
\hline Numuneler & $\mathbf{P}_{\max }, \mathbf{N}$ & $\mathrm{F}_{\mathrm{s}}, \mathbf{M P a}$ & F $_{\text {sqave. }}$ & $\mathbf{F}_{\mathrm{s}, \mathrm{std}}$ & $\sigma, \mathbf{M P a}$ & $\sigma_{\text {ave }}$ & $\sigma_{\text {std }}$ \\
\hline \multirow{3}{*}{ CF.W.P3.D8.T26 } & 1062,5 & 0,267 & \multirow{3}{*}{0,242} & \multirow{3}{*}{0,020} & 36,381 & \multirow{3}{*}{32,992} & \multirow{3}{*}{2,710} \\
\hline & 959,375 & 0,241 & & & 32,850 & & \\
\hline & 868,75 & 0,218 & & & 29,747 & & \\
\hline \multirow{3}{*}{ CF.W.P3.D8.T20 } & 984,375 & 0,319 & \multirow{3}{*}{0,306} & \multirow{3}{*}{0,015} & 42,748 & \multirow{3}{*}{41,029} & \multirow{3}{*}{2,059} \\
\hline & 971,875 & 0,315 & & & 42,206 & & \\
\hline & 878,125 & 0,285 & & & 38,134 & & \\
\hline \multirow{3}{*}{ CF.W.P3.D8.T16 } & 875 & 0,350 & \multirow{3}{*}{0,330} & \multirow{3}{*}{0,014} & 38,869 & \multirow{3}{*}{36,695} & \multirow{3}{*}{1,547} \\
\hline & 796,875 & 0,319 & & & 35,399 & & \\
\hline & 806,25 & 0,322 & & & 35,815 & & \\
\hline
\end{tabular}

$\sigma=\frac{P_{\max } \cdot S}{2 t \cdot(d+c) \cdot b}$

$\sigma=y u ̈ z e y$ gerilmesi, $M P a$

$d=$ yüzey kalınlı̆̆l, $\mathrm{mm}$

$S=$ açıklık mesafesi, $\mathrm{mm}$

$b=$ sandviç genişliği, $\mathrm{mm}$ 
Eşitliklerde de görüldüğü gibi sandviç yapının dayanabildiği maksimum kuvvet dikkate alınmaktadır. Diğer terimler ise Şekil 1 'de belirtilen sandviç yapının geometrisinden elde edilmektedir. Çizelge 6'da hesaplamalara ait sonuçlar verilmiştir.

\subsection{Numunelerde Meydana Gelen Hasarlar}

Eğilme testi sonrasında numunelerde meydana gelen hasar durumları stereomikroskop ve $30 \mathrm{~mm}$ F/3,5 ölçülerinde makrolense sahip fotoğraf makinesi kullanılarak makro düzeyde incelenmiştir. Çekirdek malzemede meydana gelen hasar durumu çökme ve ezilme şeklinde olurken, yüzey tabakalarda ise elyafta çatlamalar ve devamında kırılma sseklindedir. Ancak artan çekirdek kalınlığı ile birlikte alt yüzey tabakada hasar görülmemektedir. Şekil 12'de kullanılan çekirdek kalınlığına göre sandviç plakalarda meydana gelen çekirdek ezilmesi ve çökme durumları görülmektedir.

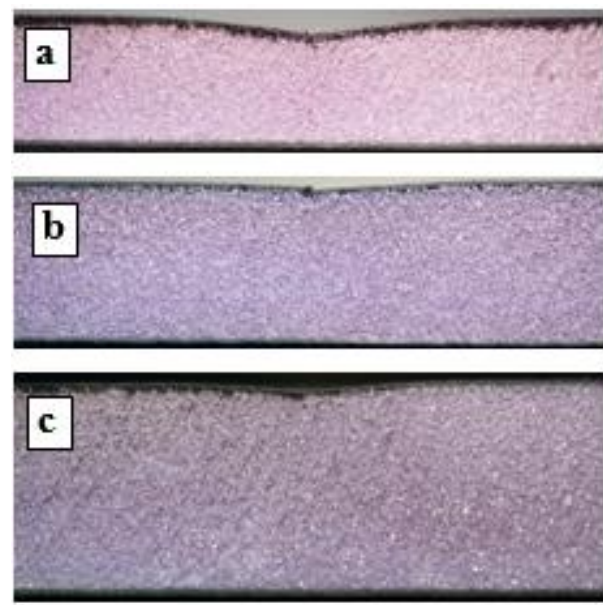

Şekil 12. Sandviç plakalarda oluşan hasarlar;
(a) CF.W.P3.D8.T16
(b) CF.W.P3.D8.T20
(c) CF.W.P3.D8.T26

Yüzey tabakaları incelendiğinde ise yine sandviç plakalarda kullanılan çekirdek kalınlıklarına bağlı olarak meydana gelen hasarlar değişkenlik göstermektedir. $16 \mathrm{~mm}$ çekirdek kalınlığına sahip sandviç plakanın yüzey tabakasında buruşmalar (wrinkling) gözlenmiştir ve elyaf kırılmaları 20 ve
26 mm çekirdek kalınlığına sahip sandviç plakalara göre daha şiddetlidir. Ayrıca 20 ve 26 mm çekirdek kalınlığına sahip sandviç plakaların alt yüzey tabakalarında kırılma olmazken $16 \mathrm{~mm}$ çekirdek kalınlığına sahip sandviç plakanın alt yüzeyinde elyaf kırılmaları meydana gelmiş ve malzeme tamamen koparak ikiye ayrılmıştır. Şekil 13'te numunelerin üst yüzey tabakalarda meydana gelen elyaf hasarları görülmektedir.

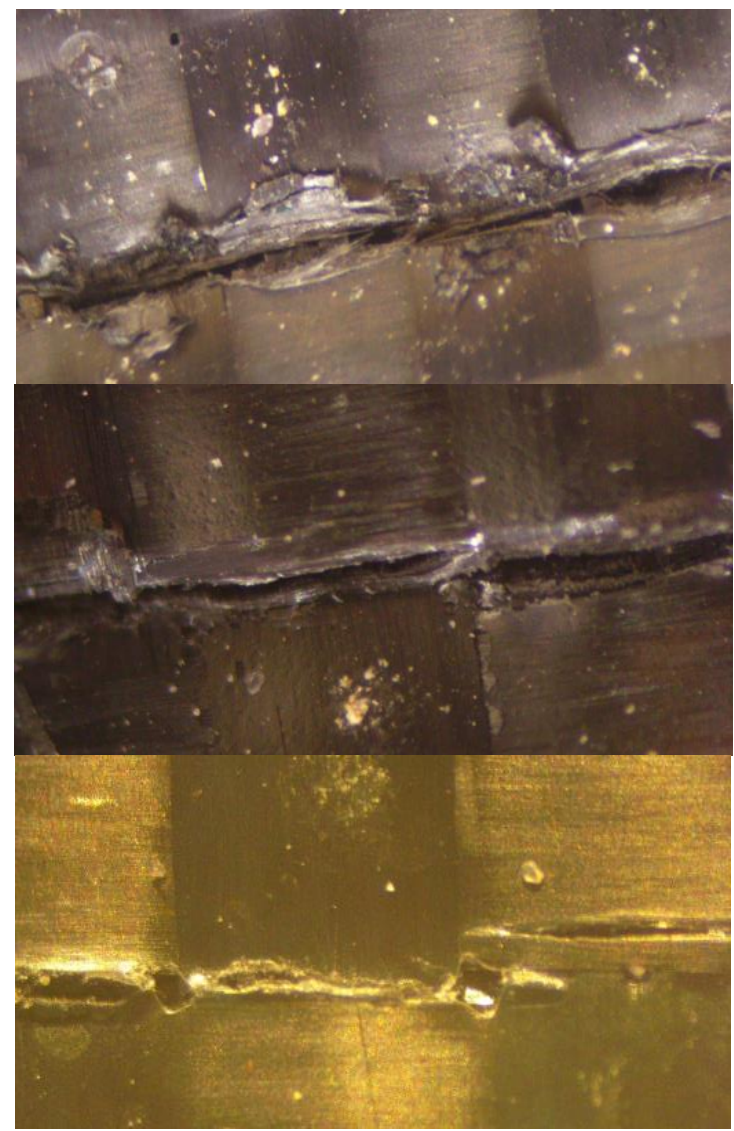

Şekil 13. Üst yüzey tabakada meydana gelen elyaf hasarlar1; (a) CF.W.P3.D8.T16

(b) CF.W.P3.D8.T20

(c) CF.W.P3.D8.T26

\section{TARTIŞMA VE SONUÇ}

Sandviç yapılı kompozit malzemelerde beklenen en önemli fayda oldukça hafif, rijit ve eğilme yüklerine karşı dirençli paneller üretilmesi ve geliştirilmesidir. $\mathrm{Bu}$ çalışmada aynı çekirdek 
türüne ait farklı kalınlıklarda (16-20-26 mm) PVC köpük malzemeleri ve örgü dizilimli karbon elyaf kumaşlar kullanılarak sandviç plakalar üretilmiş ve üç nokta eğilme testine tabi tutulmuştur. Şekil 11'den de görüldüğü gibi çekirdek kalınlığının artması ile malzemenin eğilme direnci iyileşmiş ve yük taşıma kapasitesi artmıştır. Yoğunluğu oldukça düşük PVC köpük sayesinde malzeme ağırlığında fazla bir değişiklik olmaması bir diğer avantajı olup sandviç yapıların temel prensibi ile de uyuşmaktadır [18]. Şekil 11'de elde edilen kuvvet-deplasman eğrilerine baktığımızda malzemenin eğilmeye karşı davranışını üç aşamada yorumlamak mümkündür. İlk aşamada kuvvet yüksek bir eğimle belirli bir noktaya kadar lineer artmış devamında ise eğri lineer olmayan ve düşük bir eğimle artarak maksimum yüke ulaşmıştır. Maksimum yüke ulaştığı noktada üst yüzey tabakalarda elyaf hasarları meydana gelmiş olup tabakada kırılma neticesinde çekirdek malzeme ezilerek yükü taşımaya devam etmiştir. 20 ve $26 \mathrm{~mm}$ çekirdek kalınlığına sahip sandviç plakalarda ani yük azalması ve devamında yükün çekirdek malzeme tarafından taşınması söz konusu iken, $16 \mathrm{~mm}$ çekirdek kalınlığına sahip sandviç yapıda plaka tamamen kırılıp ikiye ayrılana kadar yükte azalma devam etmektedir. Testler tamamlandiktan sona malzemelerde oluşan hasarlar da incelenmiş olup Şekil 12'de de görüldüğü gibi çekirdek kalınlığının artması ile malzemenin eğilmeye karşı gösterdiği direncin de arttığı gözlemlenmiş̧tir.

\section{TEŞEKKÜR}

$\mathrm{Bu}$ çalışma, FBA-2016-6610 nolu proje kapsamında yapılmış olup Çukurova Üniversitesi Rektörlüğü BAP Koordinasyon Birimi tarafindan desteklenmiştir.

\section{KAYNAKLAR}

1. Ronald, F. G., 2012. Principles of Composite Material Mechanics, 3rd Edition. CRC Press.

2. Tortoç, A., 2009. Balsa/Pvc Sandviç Yapılarda Kırılma Tokluğu Etkisinin Nümerik Çalışması, Yüksek Lisans Tezi, Dokuz Eylül Üniversitesi, Fen Bilimleri Enstitüsü, İzmir.
3. Carlsson, L. A., Kardomateas, G. A., 2011. Structural and Failure Mechanics of Sandwich Composites. Springer.

4. Kara, E., 2012. Çeşitli Elyaf Dizilimleriyle Oluşturulmuş Metal Köpük Çekirdekli Sandviç Kompozitlerin Mekanik Davranışlarının İncelenmesi, Yüksek Lisans Tezi, Hitit Üniversitesi, Fen Bilimleri Enstitüsü, Çorum.

5. Daniel, I. M., Gdoutos, E. E., Wang, K. A., Abot, J. L., 2002. Failure Modes of Composite Sandwich Beams. International Journal of Damage Mechanics, Vol. 11, p. 309-334.

6. Mallick, P. K., 2007. Fiber-Reinforced Composites: Materials, Manufacturing, and Design. CRC Press.

7. Harte, A. M., Fleck, N. A., Ashby, M. F., 2000. Sandwich Panel Design using Aluminum Alloy Foam. Advanced Engineering Materials, 2, No. 4, p. 219-222.

8. Kulkarni, N., Mahfuz, H., Melanie, S., Carlson, L.A., 2004. Fatigue Failure Mechanism and Crack Growth in Foam Core Sandwich Composites under Flexural Loading, Journal of Reinforced Plastics \& Composites, 23(1), p. 83-94.

9. Lim, T.S., Lee, C.S., Lee, D.G., 2004. Failure Modes of Foam Core Sandwich Beams under Static and Impact Loads, Journal of Composite Materials, 38(18), p. 1639-1662.

10. Steeves, C.A., Fleck, N.A., 2004. Collapse Mechanisms of Sandwich Beams with Composite Faces and a Foam Core, Loadedin Three-point Bending. Part I: Analytical Models and Minimum Weight Design. International Journal of Mechanical Sciences, 46, p. 561-583.

11. M. Zabihpoor, M., Adibnazari, S., Moslemian, R., Abedian, A., 2007. Mechanisms of Fatigue Damage in Foam Core Sandwich Composites with Unsymmetrical Carbon/Glass Face Sheets. Journal of Reinforced Plastics And Composites, Vol. 26, No. 17/2007, p. 1831-1842.

12. Atas, C., Sevim, C., 2010. On the Impact Response of Sandwich Composites with Cores of Balsa Wood and PVC foam. Composite Structures, 93, p. 40-48.

13. Bey, K. C., Gilgert, J., Azari, Z., 2012. Behaviour of composite sandwich foam- 
Sandviç Malzeme Geliştirmede Polimer Köpük Çekirdek Kalınlığının Eğilme Dayanımına Etkisinin Deneysel olarak Araştırılması

laminated glass/epoxy under solicitation static and fatigue. Composites: Part B, 43, p. $1178-1184$.

14.Zhou, J., Hassan, M. Z., Guan, Z., Cantwell, W. J., 2012. The Low Velocity Impact Response of Foam-based Sandwich Panels. Composites Science and Technology, 72, p. 1781-1790.

15. Ozdemir, O., Karakuzu, R., Al-Shamary, A. K. J., 2015. Core-thickness Effect on the Impact Response of Sandwich Composites with Poly (vinyl chloride) and Poly (ethylene terephthalate) Foam Cores. Journal of Composite Materials, Vol. 49(11), p. 1315-1329.

16. Styles, M., Compston, P., Kalyanasundaram, S., 2006. The Effect of Core Thickness on the Flexural Behaviour of Aluminium Foam Sandwich Structures. Composite Structures 80 (2007) p. 532-538.

17. ASTM C393/ M 393C. Standard Test Method for Core Shear Properties of Sandwich Constructions by Beam Flexure. Annual Book of ASTM Standards. ASTM International, United States, 2011.

18. DIAB Group, 2012. DIAB Guide to Core and Sandwich, Sweden. www.diabgroup.com 